Alexander Bielicki ${ }^{1}$ :

\title{
Societal trust and nation-thinking in the midst of a pandemic - Central Europe and Scandinavia
}

Trust in those who lead the government, trust in the way society is ordered, and trust in other people can all influence how individuals perceive the country in which they live. This study examines the different facets of societal trust (the complex network of state, political, national and social trust) in four European countries Norway, Sweden, Slovakia and the Czech Republic - and connects these with how people understand their society to be organized, especially the degree to which the national frame is relevant. The results presented from these four countries offer a more nuanced picture of what it means to have trust in government and institutions and what it means to have trust in those who inhabit one's country, especially in a time of crisis. The main data sources are identical surveys in four languages.

\section{Introduction}

This study sets out to examine societal trust in relation to the salience of nationalism (nation-thinking) in two sets of European countries: Norway and Sweden with their reportedly high levels of accumulated social trust, and Slovakia and Czechia with their reportedly low levels of accumulated social trust. While questions about the salience of the nation are perennial in nature, questions about social trust and political trust have perhaps become even more prevalent during the COVID-19 pandemic. By examining these different facets of societal trust, one should be able to get a nuanced picture of the internal highs and lows when it comes to trust, and gain better understanding about the role that the nation and national differentiation play in societal trust. The data used to examine these relationships comes primarily from the results of a survey campaign in May and June 2000.

As framed, this research attempts to accomplish a number of tasks. First, it seeks to examine some of the constitutive elements of societal trust in the four countries in question. Categorizing countries simply as high trust or low trust countries does not tell the whole story. In order to counter broad generalizations regarding social trust in Scandinavia and Central Europe, this analysis shows the internal highs and lows of societal trust, giving a more nuanced picture of who and what receives the trust of respondents. Trust in government might be low, but trust in strangers can be high. The inverse is also possible. However, even estimations such as this are not complete as trust for groups and institutions may also be highly contextual. In addition, the survey asks respondents to differentiate between various levels of societal organization: respondents evaluate their levels of trust and attachments along various geographic divisions such as local lines, regional lines, national lines and beyond. This research also delves into people's perceptions of equality/inequality and diversity/homogeneity in their home countries and analyzes them in connection with respondents' reliance on

\footnotetext{
${ }^{1} \mathrm{PhD}$, Senior Research Fellow, iASK - Institute of Advanced Studies Köszeg, Lecturer, University of Oslo DOI: 10.14267/RETP2021.02.05
} 
the national frame. While I will not go into perceptions of equality and diversity in this article, some of the data from this section of the survey will be alluded to here. Lastly, I seek to situate all of this in the context of the pandemic situation in the late spring of 2020.

As mentioned, two pairs of countries are examined here: Slovakia - Czechia and Sweden - Norway. The former exhibit low trust on a European level and the latter exhibit high trust on a European level. The countries have similar population sizes and comparative populations. Both pairs include one country with about 5.5 million inhabitants (Slovakia, Norway) and both pairs include one country with a bit over 10 million inhabitants (Czechia, Sweden). There is a general perception that Norway and Sweden exhibit high levels of equality and that Czechia and Slovakia exhibit higher levels of inequality, although this is somewhat tampered by the decades under communism that flattened the inequality curve to a large degree. In addition, both pairs were single countries in relatively recent history, each with a dominant partner and a lesser partner. They exhibit similar dynamics of othering (big brother, little brother relationships) with Czechia and Sweden considered more cosmopolitan, and Norway and Slovakia more provincial/parochial. These relationships make each of the paired countries their most significant comparative other.

In this article, I will first present the topic in focus: trust and the national frame. I will then share some of the survey responses that pertain to societal trust: trust ratings for groups and institutions, ratings of reliance on various groups and institutions and feelings of attachment to various social groupings. Following that, I will explore trust ratings specifically in the context of the pandemic. Lastly, the degree to which the national frame is salient for respondents will be examined in connection to trust ratings.

\section{Trust, distrust and the nation}

Societal diversity can break down the trust which is sought after in a stable democracy [Putnam, 2007]. Social inequality, especially in the form of income inequality, can also accelerate distrust within society [Wilkinson and Pickett, 2009] and it has been hinted that this connection may be more robust in the case of European states [Delhey and Dragolov, 2013]. Diversity and inequality disrupt the perceived values of equality among the members of a given society. If a society's cohesiveness is built upon equality or the promise of equality, perceptions of largescale difference among the population can stress the system if there are no salient crosscutting identities to mitigate the stress. Separately, and in concert with one another, these factors shape the potential relationships between the peoples of a nation-state by influencing who can be considered within the discursively constructed "us". Examining these societal influences on trust are of immense importance, especially in the midst of a crisis when social solidarity and governmental trust are certainly put to the test.

While significant research has been done on the relationships between trust and equality and trust and diversity, no studies have taken this research further to determine what role these relationships play in the everyday salience of nationalism. By the term nationalism, I refer to "a way of talking, writing, and thinking about the basic units of culture, politics, and belonging that helps to constitute nations as real and powerful dimensions of social life" [Calhoun, 2007]. Furthermore, I focus on the ways that nationhood is enacted in the speech, actions, choices and consumption patterns of everyday individuals [Fox and Miller-Idriss, 2008]. Everyday nationhood, which echoes the call from Michael Billig to notice the unconscious and banal uses of the nation in speech and symbols [Billig, 1995], helps to describe the discursive and practical possibilities for using the 
nation as a salient form of difference-making. An additional important dimension of the research plan of everyday nationhood, is that it locates the transmission and growth of the national frame not within the discourse of ruling elites, but in the practical language and behaviors of everyday individuals. In this study, the behaviors of everyday individuals are present in the form respondents' choices and their reliance on the national frame. Several questions in the survey focus exactly on those types of everyday discourses and understandings.

Important to note is that the project focuses on individuals' perceptions of trustworthiness, fairness and equality within their home societies and not on actual measurements. To help give a more complete picture, I incorporate survey questions that measure perceived levels of trust within society, when it comes to local, regional and national institutions. I anticipate that the levels of institutional trust within society will have some sort of correlation with the prevalence of nation-thinking. Albertazzi and McDonnell [2008] point to distrust in ruling elites as a prerequisite for the growth in nationalist claims which can accompany populism. This does not mean that distrust in democratic institutions necessarily precedes, accompanies or follows growing nationalism, but rather distrust in those who hold office in these public institutions has a correlation to growing nationalism. In order to better understand the relationship between societal trust and trust in institutions, as well as to control for this significant variable, institutional perceptions will be included in this survey on trust and nation-thinking.

Analyzing trust or distrust is of paramount importance in assessing national cohesiveness and therefore national security issues. One Eurobarometer survey of Europeans' attitudes towards security [Special Eurobarometer 464b, 2017] looks at Europeans' feeling of safety and security in the home community, in their country and in the EU, but it focuses on external threats and internal criminal threats. It does not consider the level of distrust within a society as a significant threat. Another Eurobarometer survey from 2017, Designing Europe's Future (461), takes trust in institutions as a major subtopic of inquiry. Roughly following the results of this inquiry, I have chosen two countries that exhibit a pattern of trust in national governments and institutions (Norway and Sweden) and two countries that exhibit a pattern of distrust in national institutions and governments (Slovakia and Czechia).

The Eurobarometer surveys suggest that those in an economically precarious position are less trustful of national governments than those who are economically stable. Additionally, generally speaking, those with lower levels of education are more distrustful than those who have attained higher levels of education. But how does this affect the level of nationalism within a society? Research suggests that European nationalist movements often find most recruits in the lower or working classes. However, in Scandinavia, nationalist movements more often recruit from the middle classes. Economic marginalization alone does not explain this relationship. Therefore, looking towards perceptions of fairness, equality and diversity in connection with trust can give us a more detailed look at these domestic processes that strengthen national salience.

Trust is the most significant and repeated concept in the survey campaign. I ask about trust in three different ways: one, by directly asking about the levels of trust a respondent feels toward certain groups; two, by asking about what groups an individual feels they can count on; and three, by asking about the degree of respondents' personal connection to various groups, as trust is closely related to the attachments an individual may feel. These three pathways toward measuring trust reflect different ways of conceptualizing what trust means. Trust is abstract, so including these different conceptualization helps us to get a better overall picture of trust. 
Perhaps more importantly, trust is not only abstract, but highly contextual. This requires an examination of the "when" of trust, or rather, how trust is contextual or conditional. One may say, "I trust my brother if I get into a physical confrontation, but I don't trust him with my stock portfolio.” Instead of determining if individuals trust, for example, the government in general; I set out to determine in what contexts individuals may trust the government, i.e. trust to maintain order and deliver essential services, but not to direct the public life of citizens. This understanding of trust relates closely to questions regarding the dividing line between public and private. In democratic societies, we could also conceptualize the right-left political spectrum as a sliding scale for how many spheres of influence in which we trust the state to operate. Of course, there are notable exceptions when it comes to political issues conceived as religious or moral issues.

In the survey, I ask individuals directly about trust in ethnic co-nationals; however, I also gave respondents the space to reframe the distinctions of otherness and solidarity in their countries. In addition, in survey questions, I have distinguished between ethnic co-nationals and citizens. I have not asked directly about non-citizen residents. In this particular survey, it was more important to look at the phenomenon that Putnam describes as "hunkering down"; in other words, not necessarily who people do not trust, but simply if they do trust or not. Ideally, I want to capture the level of trust felt across different groups of people within society and not against specific groups.

National attachments and supranational attachments do not have a zero-sum relationship. Contrary to messages from many politicians, it doesn't have to be an "either/or" situation. Research from Castano [2004] and Duchesne and Frognier [2008], looking at local, regional, national and supranational identity, demonstrates that high- or low-level attachments to one level does not preclude high- or low-level attachments to another level. However, it hints at two things: (1) since many European political conflicts are currently constructed around an axis that pits national against supranational, there can be large impediments to establishing high levels of attachment to both levels at the same time, and (2) in general, adjacent levels can often feature complications like competition over who has decision-making competencies (i.e. independence movements, as an extreme example). High local and high national attachments, high regional and high supranational attachments; these types of formulations can be easier to maintain that adjacent levels like high national and high supranational attachments. In these relationships, we see examples of nesting identities, conflicting identities, "concordant" identities (Deutsch 2006: 166), as well as others.

\section{The Survey}

While the greater research project utilizes a mix of methods in its data collection, here I will focus mainly on the survey data. The survey questions ask respondents about their trust and attachment to various groups and institutions in the context of the pandemic. The questions garner numerical responses as well as user-generated text-based responses. These text-based responses allow respondents to define, in essence, their understanding of the concepts that feature most heavily in the survey, thereby demonstrating the ways in which the respondents understand, reproduce, challenge or even redefine the dominant understandings of trustworthiness, equality/inequality and homogeneity/diversity. While respondents are given an opportunity to essentially define how they understand some of the major concepts featured in this survey, they have not been given the opportunity to define the social groupings that they find most salient. They are asked to respond about the trust 
they hold towards named social groupings or the attachment they feel towards them. This of course influences the individuals surveyed.

The survey is 33 questions in length. Twenty-nine of the questions use an 11-point linear numeric scale (0-10) with a number of the questions grouped in multiple rating matrices, three questions collect user-generated textbased responses of up to one sentence in length, and one question uses a modified 7-point Likert scale. The questions in the survey are suited specifically to the four countries in focus. In addition, I have asked respondents to provide some additional information about themselves at the conclusion of the survey. The survey does not collect any personal information about the respondents other than from four voluntary questions at the end of the survey. These questions ask how old the respondents are, where they get their news, what party they voted for in the last election and if they participate in any membership organizations. Respondents range in age from 18 years-old to 77 years-old, with the majority of respondents in their 30s, 40s and 50s. In all four countries, political views and worldviews are strongly linked to the choice of media consumed and the surveys yielded a good distribution of preferred news sources.

The number of respondents for these online surveys was unfortunately rather small, though the amount of data generated was still rather large. This survey was shared primarily on Facebook so as to collect a greater age range than might be met through other social media platforms. The surveys were posted online in the end of May 2020 and were open for one month, which yielded just over 30 respondents each for Slovakia, Czechia and Norway. For Sweden, there were even fewer.

\section{Forms of political trust: governmental trust and institutional trust}

In my approach to the creating this survey, I wanted to add further nuance to the idea of societal trust. First, I separate societal trust in political and social trust. Next, I divide political trust into two separate spheres: governmental and institutional. I divide social trust into two overlapping spheres: generalized social trust (i.e. trust in strangers) and national trust (i.e. trust in your national community). In other words, at both the political level and the general social level, I ask respondents to evaluate both a what and a who. Governmental trust refers to those elected officials who are currently in power in a given country - a who. Institutional trust refers to the established state agencies and bureaucracies that are a bit less dynamic in nature - a what. Similarly, generalized social trust refers to individuals or strangers in society - a who - while national trust refers to a community of individuals - a what.

\section{Governmental trust}

When asked if respondents trust the current government in each respective country, the general level of governmental trust varied greatly. In Norway, nearly $70 \%$ of respondents stated that they either fully or partially trust the government and a very low percentage of respondents stated that they did not trust the government: $6.2 \%$ saying that they do not trust the government and $15.6 \%$ saying that they usually trust the government but not this particular government. In Slovakia, the majority of respondents were more lukewarm in their response. Over $60 \%$ of respondents stated that they either trusted the government very little or only somewhat. A significant number of respondents gave a conditional response: around $14 \%$ stated that they 
usually do not trust the government but they trust the current government and around $17 \%$ stated that they usually trust the government but they do not trust the current government. In Czechia, the responses were divided across the trust spectrum with a higher percentage demonstrating low levels of trust in the government: $56 \%$ stated that they either did not trust the government or they trusted them very little. In Sweden, all of the few respondents espoused high levels of trust for the government.

In general, the survey responses seem to indicate a rather high level of governmental trust in Norway. This is especially interesting given the fact that the government in power at the time of this survey was a rightwing government and only $13 \%$ of the respondents stated that they voted for one of the parties in the ruling coalition during the previous election. These results emphasize the high level of governmental trust in the country. However, when asked if they trust the current government to properly handle the COVID-19 situation, respondents returned a trust score average of 6.45 out of $10(\sigma 2.39)$. The corresponding result for Slovakia was a trust score average of 5.07 ( $\sigma$ 2.35), while the trust score average for Czechia was even lower at $4.58(\sigma$ 3.10). While not statistically relevant due to the low number of responses, the average trust score for Sweden was $6.75(\sigma 2.17)$. In general, the results for governmental trust in each of the four countries aligns with the expected results: rather high levels of governmental trust in the Scandinavian countries and markedly lower levels of governmental trust in the Central European countries. However, examining governmental trust alone does not give a complete picture of political trust in a country.

\section{Institutional trust}

The surveys do not only capture governmental trust; they also capture institutional trust. In one question that asks if state institutions can be trusted to deliver important services, the Norwegian respondents return a trust score much higher than that given to the government, $7.45(\sigma 2.15)$. Respondents in Slovakia also returned a much higher institutional trust score than governmental trust score, 6.45 ( $\sigma$ 2.25). Respondents in Czechia returned, comparatively speaking, an even higher institutional trust score, 6.53 ( $\sigma$ 2.86), considering the governmental trust score was even lower than in Slovakia. Respondents in Sweden all gave high trust scores to institutions in the country.

Institutional trust appears to be quite high in all four countries in question. In Sweden and Norway, over $75 \%$ of respondents gave scores of 7 or higher when asked how much they trust state institutions to deliver essential services. The majority of respondents from Slovakia and Czechia gave scores of 7 or higher as well, though there were a significant number of very low scores as well. Numbers that reflect institutional trust tell an important story. High institutional trust in Scandinavia is not unexpected, but it is underreported in Central Europe. Despite the fact that Slovakia and Czechia exhibit low levels of governmental trust and relatively low levels of generalized social trust, there are nevertheless stores of accumulated trust in society, and state institutions are the recipients of this trust. 
Table 1 - International and Supranational Institutional Trust: Do what extent to you trust the following institutions? (0-low trust, 10 - high trust)

\begin{tabular}{|l|l|l|l|}
\hline & $\begin{array}{l}\text { European Union - mean } \\
\text { [standard deviation] }\end{array}$ & $\begin{array}{l}\text { World Health Org. - mean } \\
\text { [standard deviation] }\end{array}$ & $\begin{array}{l}\text { United Nations - mean } \\
\text { [standard deviation] }\end{array}$ \\
\hline Norway & $5.20[\sigma 2.75]$ & $6.45[\sigma 3.37]$ & $6.24[\sigma 3.21]$ \\
\hline Slovakia & $6.52[\sigma 2.25]$ & $5.83[\sigma 2.35]$ & $5.75[\sigma 2.49]$ \\
\hline Czechia & $4.24[\sigma 3.17]$ & $4.15[\sigma 2.75]$ & $4.52[\sigma 03.05]$ \\
\hline Sweden & $* 5.50[\sigma 1.80]$ & $* 7.25[\sigma 2.49]$ & $* 6.50[\sigma 2.06]$ \\
\hline
\end{tabular}

"not statistically relevant due to low number of responses

I also asked about trust in institutions outside of the state, one supranational institution (the European Union) and two international (the World Health Organization and the United Nations). Respondents from Slovakia were the only group to report a high level of trust to the EU, with nearly $60 \%$ of responses at 7 or higher. In the case of the Czech Republic, 50\% of the respondents gave the EU a score of 3 or lower. The average scores from Czech Republic, Sweden and Norway were all between 5 and 6, but the high standard deviations show that there was a high level of disagreement about the answers to these questions. Slovakia was the only country from which the average response was above 6. It should be noted that Norway is the only country that is not a member of the European Union.

Respondents from Slovakia and the Czech Republic exhibited even lower levels of trust for the World Health Organization, markedly lower in the Slovakia and only somewhat lower in Czechia. Unsurprisingly, the WHO scored much higher in Norway than did the European Union.

Czechia's average score for trust given to the UN was just above 4 , due to $18 \%$ of the respondents giving a zero score to the UN. For Slovakia, the average score was nearly 6 out of 10 . The majority of scores from Norway were above 7; however, $15 \%$ of the respondents gave a zero score to trust in the UN. The limited data from Sweden shows a similar trend. Overall, the responses show a clear pattern of huge divisions within society regarded the perception of supranational and international institutions. In other words, these institutions received a number of very high and very low scores (evidenced by the high standard deviations), demonstrating that there is a significant amount of polarization in these countries when it comes to perceptions of international organizations. In none of the countries measured did any domestic institutions receive such low scores or such dramatic splits in the scores given. Only when it comes to the trustworthiness of politicians did respondents also give some zero scores as well. Predominantly, domestic institutions, received 1) generally higher scores than international institutions and 2) generally more clustered scores with fewer large splits in the scores given. So, regardless of respondents' perceptions of international institutions, they gave relatively similar scores for domestic institutions. Therefore, institutional trust seems to be high in each of the four countries in question. This does not necessarily mean that all state institutions are evaluated equally. Respondents were asked only to give their perception of state institutions in general, not specific institutions. 


\section{Forms of Social trust: Generalized social trust \& national trust}

The surveys also looked at generalized social trust, i.e. trust in strangers. I added a national component as well, asking both about other people living in the country and other people who shared the same national identity/ethnicity. In all four countries in question, the level of trust exhibited by the respondents is roughly the same for stranger co-residents and stranger co-nationals. This was not a huge surprise as both of these conceptualizations can be construed to represent the national "us", especially in the case of Norway and Sweden. However, it was important to plant this nationally framed differentiation early in the survey, as many of the later questions try to determine what in-group holds the most salience for the respondents and what are the limits of the trust given to relevant in-groups. In Norway and Sweden, asking about ethnicity/national identity and preferences could be perceived as awkward. This is further complicated by the fact that there exist markedly different understandings within these countries regarding who is considered to be a member of the nation and who is kept out of the national community. Interpreting national identity as ethnicity has a strong history in all four countries in question, but the past decades have seen challenges to that dominant understanding in Scandinavia. There are significant segments of the population in both Sweden and Norway that interpret national identity in terms of citizenship and culture, as opposed to ethnicity or race. Ethnicity and race are still key components of national identity in these countries, but they are not often made explicit. In the Czech Republic, questions regarding national identity are also considered to be a bit awkward, but for a different reason. Due to a variety of historical circumstances, there today exists a relatively low level of attachment to national identity throughout the Czech Republic. As a multi-ethnic state, national differentiation has become engrained in the social and political life of Slovakia, so these questions would not be considered as awkward among survey respondents. Some of these interpretations were echoed by some colleagues who edited the language on the surveys or offered feedback on the questions. Colleagues in Sweden and Czechia responded that they thought respondents might be uncomfortable with (or at very least unaccustomed to) answering questions that took ethnicity into consideration and made it explicit.

\section{Reliance as trust}

In order to gain a fuller picture of respondents' trust, the survey asks them not only to declare their trust in a variety of groups and institutions, but to rate the degree to which they feel they can rely on various groups. I include this additional dimension of trust for a variety of reasons. First, trust as a concept may not be easily defined and different respondents will likely have slightly differing understandings of what it means to trust; therefore, I wanted to include differing dimensions of what trust might mean. Second, trust, especially in its verb form, translates slightly differently in the four languages used for the survey. These linguistic differences, even when subtle, can have an effect on how trust is conceptualized; therefore, the more ways to access respondents' levels of trust, the more detailed the picture that emerges. 
Table 2-Reliance as Trust: To what extent to you feel that you can rely upon the following groups and institutions? (0- not at all, 10-completely)

\begin{tabular}{|l|c|c|c|c|c|}
\hline & $\begin{array}{c}\text { Neighbors - } \\
\text { mean [SD] }\end{array}$ & $\begin{array}{c}\text { Local } \\
\text { government - } \\
\text { mean [SD] }\end{array}$ & $\begin{array}{c}\text { State } \\
\text { government - } \\
\text { mean [SD] }\end{array}$ & $\begin{array}{c}\text { Co-nationals - } \\
\text { mean [SD] }\end{array}$ & $\begin{array}{c}\text { Others regardless of } \\
\text { nationality/ethnicity } \\
\text { - mean [SD] }\end{array}$ \\
\hline Norway & $7.15[\sigma 1.80]$ & $6.81[\sigma 2.20]$ & $6.15[\sigma 2.67]$ & $6.87[\sigma 1.81]$ & $6.52[\sigma 1.78]$ \\
\hline Slovakia & $6.93[\sigma 2.42]$ & $5.93[\sigma 1.92]$ & $4.62[\sigma 2.11]$ & $5.57[\sigma 1.80]$ & $5.90[\sigma 1.73]$ \\
\hline Czechia & $5.79[\sigma 2.95]$ & $5.23[\sigma 2.41]$ & $3.81[\sigma 2.61]$ & $5.31[\sigma 2.24]$ & $5.24[\sigma 2.16]$ \\
\hline Sweden & $* 8.25[\sigma 1.48]$ & $* 7.25[\sigma 0.83]$ & $* 8.00[\sigma 0.71]$ & $* 7.50[\sigma 0.50]$ & $* 7.33[\sigma 0.47]$ \\
\hline
\end{tabular}

*not statistically relevant

Table 2 shows the degree to which respondents feel they can rely upon certain groups and institutions. While the data from Sweden is not statistically relevant, the general picture shows very high reliance on neighbors and quite high reliance on government and people. On the whole, the data is marked by generally high levels of confidence that people can rely on others in society in the Scandinavian countries. For all four countries, respondents give the highest reliability rating to their neighbors. Also of relevance is the low degree to which people feel they can rely on the state government, especially in the cases of Slovakia and Czechia. In contrast, the surveys from Norway, Slovakia and Czechia rated the reliability of local government significantly higher than that of state government.

The low standard deviations (under $\sigma 2.00$ ) found among the responses from Norway indicate a great deal of consensus when it comes to trusting neighbors, co-nationals and others regardless of nationality or ethnicity. The low standard deviations found among the response from Slovakia indicate a great deal of consensus when it comes to trusting local government, co-nationals and others regardless of nationality or ethnicity. The higher standard deviations among the responses from the Czech Republic indicate a greater degree of volatility or disagreement regarding the degree upon which these groups and institutions can be relied.

The surveys from Slovakia show one other extremely interesting trend: that co-nationals receive a lower reliability score (5.57) than others in society regardless of their ethnicity or nationality (5.90). The low standard deviations demonstrate that there is a rather strong degree of consensus around these estimations, and this assessment is repeated in the answers to other survey questions. One possible explanation for this can be connected to the way in which Slovak society is ordered. It is the only country of the four that can be labeled a multi-ethnic state. Certainly, Sweden and Norway can be described as multicultural in nature primarily, though not completely, due to relatively recent immigration. In Slovakia, ethnicity is part of political life and part of many people's social lives, depending on where they live in the country. Ethnicity as a fundamental building block of society, therefore, becomes a part of the dominant discourse. Perhaps because it is perceived as an everyday reality, nationality has taken on a different connotation. In the other countries in question, the topic of ethnicity is often shied away from in polite conversation, yet feelings of ethnic superiority (or skepticism towards other ethnicized groups) is rather widespread throughout the general population. This seems to match with the slightly lower reliability scores for 'others regardless of ethnicity or nationality' that we see in Norway and Czechia (as well as in the limited data from Sweden). It is not my assertion that more 
publicly present discourse on nationality and ethnicity brings higher estimations of ethnic "others". There are a number of episodes in Slovak social and political life over the past decade or so that have served to partially delegitimize nationalist parties and movements in the country. Survey respondents can also be reacting to this de-legitimization of the national frame. Also, due to the small sample size, these numbers cannot be seen as representative of the country as a whole; however, they do show a number of the possible interpretations of government and society that exist in the country.

\section{Social trust in the pandemic: a reliance on national stereotypes?}

One set of questions in the survey directly relates to the COVID situation: I ask respondents to give their perceptions of the degree to which people can be trusted to follow guidelines and act in solidarity with others. Specifically, I ask respondents to rate the degree to which they could trust people in their neighborhood and the degree to which they could trust people living in neighboring countries, though I did not specify which countries. This is the only time in the survey when respondents are asked about groups living outside of their country of residence. Partially influenced by anthropologist Marianne Gullestad, I focus on neighborhood as opposed to asking about one's entire country. Gullestad finds that the way that individuals perceive their country can be highly influenced by the ways in which they experience their neighborhood [2006]. This does not necessarily mean that individuals view the country in which they live as their neighborhood writ large, although that is sometimes the case. However, individuals often imagine their country based upon how they interpret their neighborhood. So, for the purposes of these survey questions, the neighborhood was an important focus.

In Norway, respondents gave a 6.82 average out of 10 when asked if their neighbors could be trusted to follow guidelines and a 7.34 average when asked if they could rely on their neighbors to help one another if necessary. Respondents in Norway gave an average 6.52 when asked if people in neighboring countries could be trusted to follow guidelines and a 6.64 average when asked if people in neighboring countries would also help one another if necessary (see table below for complete list of average scores). As expected, the evaluation of imagined people outside of Norway brought a lower trust rating. 
Table 3 - Following Guidelines and Helping Others: To what extent do you trust people in your neighborhood/neighboring country to follow directives and guidelines/help others if necessary? (0-low trust, 10- high trust)

\begin{tabular}{|l|l|l|l|l|}
\hline & $\begin{array}{l}\text { Following } \\
\text { guidelines }- \\
\text { neighborhood } \\
\text { (avg.) }\end{array}$ & $\begin{array}{l}\text { Following } \\
\text { guidelines - } \\
\text { neighboring } \\
\text { countries (avg.) }\end{array}$ & $\begin{array}{l}\text { Helping one } \\
\text { another - } \\
\text { neighborhood } \\
\text { (avg.) }\end{array}$ & $\begin{array}{l}\text { Helping one } \\
\text { another - } \\
\text { neighboring } \\
\text { countries (avg.) }\end{array}$ \\
\hline Norway & 6.82 & 6.52 & 7.34 & 6.64 \\
\hline Slovakia & 7.21 & 6.24 & 7.17 & 6.10 \\
\hline Czechia & 6.50 & 5.35 & 7.55 & 5.47 \\
\hline Sweden & ${ }^{*} 6.75$ & ${ }^{*} 7.25$ & ${ }^{*} 7.00$ & $* 6.75$ \\
\hline
\end{tabular}

*not statistically relevant

One important thing to note is that, in general, respondents seem give higher scores when talking about giving help than when evaluating whether or not people will follow government guidelines and directives. The respondents from Slovakia provide an interesting exception to this: they gave a slightly higher average trust rating to their neighbors in regard to following guidelines (7.21) than to helping one another (7.17). This same exception appears in their evaluation of people living in neighboring countries. This evaluation of neighbors seems to correspond with the prevalent self-perception of people in Slovakia as obedient. Obedience and agreeability are prominent self-assigned national stereotypes in the country (Graf \& Hrebícková, 2011), and the fact that following guidelines receives a slightly higher score than offering assistance (and a comparatively high score in general) seems to support the prevalence of this self-understanding. I do not make any claims about the validity of this stereotype, only that this stereotype seems to have an effect on the dominant discourse. This national stereotype, however, does not necessarily support the ratings given to individuals in neighboring countries, where rule-following receives higher trust scores than helping others

When it comes to the numbers from respondents in the Czech Republic, national stereotypes can also play a significant role. Czech self-stereotypes often reference high levels of individualism and cautiousness. I do not claim that these self-perceptions are responsible for the numbers presented from this survey, but rather that they can help offer a reading of these responses. Respondents from Czechia exhibit a large difference between perceptions of neighbors' obedience versus willingness to help when necessary. Individualism and cautiousness, taken in tandem, can be represented by skepticism. One reading of the numbers that show respondents' expectations that neighbors will follow guidelines (6.50) could be informed by a healthy dose of cautiousness or skepticism, while respondents' expectations that neighbors would help if necessary (7.55) could reflect a lower level of cautiousness. The phrase "if necessary" in the question about helping others likely influences respondents to drop a bit of their skepticism. In other words, counting on one's neighbors to help in case of an emergency is a distinctly different scenario than counting on one's neighbors to do all the little things that the government is asking them to do. There is much greater immediacy when it comes to the former.

These questions also ask respondents to distinguish between neighbors complying with the government and neighbors helping concrete people, their neighbors. If the national self-stereotype of individualism is influential 
to respondents, it would be likely for them to give a lower score of trust for neighbors following along with guidelines issued by the government, as the respondents themselves might feel a bit of skepticism to dictates from the government. Respondents from the Czech Republic exhibited extremely low trust scores when it comes to the degree to which they feel that they can rely on the state government (see earlier section on Reliance).

In Norway, the fact that helping others scores higher than following guidelines seems to match with commonly held perceptions of Norwegian society, especially in regard to the concept of dugnad. "Dugnad refers to unpaid, collective, cooperative work where every member of a community is expected to participate regardless of their social position [Eriksen, 2020]." It is a ubiquitous concept in the Norwegian context, one that has been woven into the national character. Dugnad can take many forms from fixing up a community garden to the collective rebuilding effort after World War II. This idea of voluntarily helping others is engrained into the national consciousness so much so that it can hardly be called voluntary; it is expected. It is hardly surprising, then, that the expectations that neighbors will help one another are so high.

The measurements for Sweden were not statistically relevant, but showed a moderately high level of trust for both neighbors and those living in neighboring countries, roughly similar to that of Norway. These results are more-or-less in line with what would be expected. In both Sweden and Norway, there exist general perceptions of solidarity being highly valued in society, though there are certainly significant challenges to this perception as well. Also, Sweden and Norway are each other's most relevant other, along with Denmark, so it's likely that many respondents are imagining the other country. The responses to this set of survey questions highlight two important factors of social trust: that the term trust contains within it different meanings and that trust, however conceptualized, is contextual (in other words, exemplifying the when of trust).

\section{Trust and the National Frame}

In this section, I will analyze the survey data especially in reference to questions which evoke the national frame. The two most relevant questions in that sense are the ones that ask respondents about the extent to which they trust other members of their own nation and the degree to which they feel they can rely upon members of their own nation. First, let us take a look at the trust scores given to residents of one's own country versus members of one's own nation (a formulation of generalized social trust and a formulation of national trust, respectively). 
Table 4 - To what extent do you trust the following groups: other residents of your country, other members of your nation, other members of your religious (worldview) community? (0-low trust, $10-$ high trust)

\begin{tabular}{|l|c|c|c|}
\hline & $\begin{array}{c}\text { Trust in residents } \\
- \text { mean }[\mathrm{SD}]\end{array}$ & $\begin{array}{c}\text { Trust in co-nationals } \\
- \text { mean [SD] }\end{array}$ & $\begin{array}{c}\text { Trust in co-religionists } \\
- \text { mean [SD] }\end{array}$ \\
\hline Norway & $7.40[\sigma 1.46]$ & $7.34[\sigma 1.72]$ & $7.05[\sigma 2.19]$ \\
\hline Slovakia & $5.97[\sigma 1.73]$ & $5.36[\sigma 1.93]$ & $5.16[\sigma 2.75]$ \\
\hline Czechia & $5.55[\sigma 1.94]$ & $5.58[\sigma 1.95]$ & $4.75[\sigma 3.60]$ \\
\hline Sweden & ${ }^{*} 6.50[\sigma 0.87]$ & ${ }^{*} 6.33[\sigma 0.95]$ & $* 6.00[\sigma 1.00]$ \\
\hline
\end{tabular}

*not statistically relevant

In Table 4, above, notice the nearly identical trust scores given for others residents of one's country and other members of one's nation. In other words, generalized social trust and national trust appear to be roughly the same in each country except for Slovakia, where fellow co-nationals (strangers that share a group identification with the respondent) garner a lower trust rating than fellow residents (strangers that share a home country). The standard deviations indicate a rather high amount of consensus on these trust assessments for each of the countries represented. This does not necessarily mean that the national frame is not salient for many of the respondents, though it could also mean that. All that can be reliably said is that respondents have evaluated them nearly identically.

Unfortunately, the 11-point numeric scale questions on the survey cannot accurately measure the salience of the nation or national frame, but it can offer some clues. The somewhat pessimistic view of one's own nation, as shown in the responses from Slovakia, indicates a possibly diminishing salience of the national frame in the country, a de-legitimization of the national frame or an increasingly negative evaluation of the nation as an important social group. Simultaneously, we see a higher than average trust rating for the EU and high levels of European attachment. When looking at these clues, it is important to note that higher levels of national trust indicate higher entitativity, or the perception of the nation as really existing and not only abstract. The opposite cannot be said to be true: higher entitativity of the nation does not necessarily mean higher levels of national trust.

High European entitativity does not necessarily mean low national entitativity, as it is not a zero-sum game between the levels of attachment; however, given current political divisions in Europe, there is often a negative correlation between the two attachments. Since the data from the Slovakia surveys also shows high levels of trust for neighbors, rather high levels of trust and attachments to the local, as well as rather high levels of trust given to strangers in neighboring countries, this supports the idea that, among the respondents from Slovakia, ideas about their own nation and the salience of nationality are being challenged in some way.

In looking at the countries with nearly identical resident and co-national trust scores, there are some other significant points to mention. Respondents typically gave higher trust scores than reliance scores to both conationals and residents without designated nationality or ethnicity. This demonstrates that respondents likely interpret "trust" and "reliability" in different ways, despite the fact that relying on someone is one possible way 
of conceptualizing trust. This underlines the importance of asking about trust in multiple ways in order to capture respondents' diverse understandings of the concept. Also, like the trust scores shown earlier, reliance scores for co-nationals and others regardless of their nationality/ethnicity were nearly identical, except for the responses from Slovakia, where respondents gave lower reliance scores to their co-nationals.

One possible explanation for the typically flat scores for the categories 'residents' and 'co-nationals' can be found in societal norms regarding comfortableness or uncomfortableness of explicitly using the national frame, as mentioned earlier. Because of this uncomfortableness, respondents might not be willing to give drastically different answers for residents and co-nationals. It could also be that many respondents do not find those categories salient. In Slovakia, however, questions regarding nationality/ethnicity have been normalized to a certain degree. Since even before Slovak independence in 1993, national framing and national designations have been commonplace throughout society. Due to these engrained discourses and practices, taboos are largely absent from referencing ethnicity. This could be responsible for additional engagement with nationalitybased questions.

Table 5 - Question 1: To what extent do you trust that elected officials will prioritize the public over political or personal gain? (0-low trust, 10-high trust) Question 2: To what extent do you trust scientists, economists and prominent advisors in your country? ( 0 -low trust, 10 - high trust)

\begin{tabular}{|l|c|c|}
\hline & $\begin{array}{c}\text { Trust in elected officials } \\
- \text { mean [SD] }\end{array}$ & $\begin{array}{c}\text { Trust in scientists et al. } \\
- \text { mean [SD] }\end{array}$ \\
\hline Norway & $5.40[\sigma 3.05]$ & $6.78[\sigma 2.04]$ \\
\hline Slovakia & $4.31[\sigma 2.31]$ & $7.62[\sigma 1.61]$ \\
\hline Czechia & $3.29[\sigma 2.86]$ & $7.15[\sigma 2.18]$ \\
\hline Sweden & $* 7.50[\sigma 1.50]$ & $* 8.00[\sigma 1.87]$ \\
\hline
\end{tabular}

*not statistically relevant

The questions represented in Table 5 connect back to the ideas of populism and nationalism that are discussed briefly in the beginning of the paper. Albertazzi and McDonnell [2008] point to distrust in the ruling elite as one of the major prerequisites for the growing nationalist claims which often accompany populism. The type of nationalism referred to in Albertazzi and McDonnell's work can be conceptualized as not just a salience of the national frame, but an overemphasis on the national frame; something akin to Michael Billig's term "hot nationalism". The two questions presented here elicit responses that indicate the degree of danger that exists for populist movements to take hold in the countries in question. High scores on both questions would indicate a low level of danger for the rise of populist movements in the countries. Low trust scores only for elected officials and not for scientists, economists and prominent advisors signals some danger for populist movements to grow among some segments of the population, but widespread conspiracy thinking does not seem to be present. Low trust scores on both questions would indicate widespread distrust of public elites and signal a high likelihood of widespread conspiracy thinking. In other words, this would demonstrate low political trust spilling into other spheres of public life.

When it comes to trust in elected officials, Norway, Slovakia and Czechia exhibit moderate trust, moderately low trust and low trust, respectively. Especially of relevance are the high standard deviations for the trust 
scores, specifically for Norway and Czechia. The standard deviations demonstrate a high degree of disagreement among respondents. Since the average trust scores for elected officials are not very high in general, this indicates that a significant number of respondents give extremely low trust scores to elected officials, most notably the over $30 \%$ of respondents from Czechia who give elected officials a trust score of zero or one. This trend supports the development or presence of populist movements within the countries among certain segments of the population, though not widespread; however, since the trust scores for scientists, economists and prominent advisors are quite high in all of the countries (and since institutional trust remains high in all these countries, as shown earlier), this does not indicate widespread conspiracy thinking in the four countries. The trust scores from Slovakia also demonstrate a great deal of strength in society and institutions, or perhaps more accurately the ability to bend and not completely break. After numerous political scandals throughout the 2010s, one could easily expect the trust scores for elected officials to be even lower than in the Czech Republic. Nevertheless, the trust scores for elected officials are only moderately low and the trust scores for scientists, economists and advisors are very high (as is institutional trust), which signals a rather resilient democracy.

\section{Initial conclusions}

Here, I will point to a couple of my initial conclusions from the average trust, reliability and attachment scores. First, the high levels of attachment declared for one's country should be mentioned. This seems to be true across the board, regardless of the levels of political trust or social trust. Respondents also report generally high levels of attachment to Europe as well, except in the case of Czechia, where the assessments of attachment to country and Europe are nearly the same. Because of these strong attachments, we can reliably state that attachment to or identification with one's country - one form of national identity - is one of the most dominant identifications, despite the fact that the survey data does not demonstrate high degrees of national trust between individuals. We could reasonably assume that groups and institutions most closely connected with one's country have the potential to be the greatest aggregators of trust. However, we rarely see that possibility materialize. Usually only in international sporting events, like the Olympics or the World Cup, do we witness this type of phenomenon. If anything, this survey shows that our neighbors are often the greatest recipient of our trust, especially when respondents are thinking about who they trust most in the midst of a crisis.

Second, despite strong connections to one's country (and expectations that fellow countrymen follow rules better and are more willing to help others if necessary), on average, respondents did not give higher trust scores to their co-nationals. These rating were generally the same, or worse in the case of Slovakia, than the trust scores for residents of their country regardless of nationality/ethnicity. However, when it comes to reliability, respondents on average gave their co-nationals a slightly higher rating, except in the case of Slovakia. This indicates that nationality/ethnicity plays some role in processes of differentiation and evaluation (in terms of trust) even when respondents say that they do not evaluate national groupings differently (by giving identical or nearly identical trust scores).

Third, local governments receive rather high reliability ratings, certainly higher than the reliability ratings received by state governments. Local government reliability rating is interesting for a few reasons. Results show that, in general, neighbors score high; however, local attachment is not that high, so it is not local 
patriotism that primarily drives these scores. Generally speaking, respondents assessed the people living in their neighborhood, town and region to share greater similarity than people living throughout the country. Perhaps perceptions of sameness account in some small way for greater faith in local government. It could simply be that the idea of local government is valued in each of the countries. In certainly is in Norway, where a strong case can be made for decentralization having a major impact on the high institutional and governmental trust. Episodes of centralization have created major backlashes in Norwegian society, like the recent consolidation of municipalities and counties throughout the country. It is especially unfortunate that there are not enough survey results from Sweden, a country which has seen largescale centralization processes. Taken together, results from these two countries could be very telling. However, regardless of what causes this phenomenon, could reinvigorating and empowering the local be the key to restoring trust in public spheres where it is in decline? Survey results indicate that there are significant amounts of accumulated trust in local government.

Across the responses from all four countries, proximity seems to be an influential factor. Neighbors and local governments received the highest trust scores, regardless of how high or low the generalized social trust scores and political trust scores were. In addition, institutional trust seems to be high overall, which could signal a higher degree of trust in institutions than people. Interestingly, in line with the question of proximity, the Scandinavian countries are known for having prominent perceptions that there is small distance between everyday citizens and those in power, and in the case of Norway, decentralization means that state institutions often have local offices and faces, another factor that could partially explain the exceptionally high level of trust for institutions in Norway (and Sweden).

Fourth, while only alluded to in the data presented here, respondents in Slovakia and Czechia perceive a high degree of income inequality in their countries despite the fact that both countries score well on the GINI index. Inequality in society is often an influential feature in how people view strangers and should yield some significant effect on generalized social trust (i.e. trust in strangers). If actual inequality were the driver, it would be more likely to see higher generalized social trust because, according to GINI coefficients, income inequality is low in both Slovakia and Czechia. If perceived inequality were more influential, it would be more likely to see a dip in the level of generalized social trust, which seems to be the case in these survey results. While there are numerous other variables to consider, perceptions of inequality seem to be at least one of the significant influences on social trust, more so than objective inequality.

Lastly, while respondents seem to differentiate along national lines in their trust responses, the degree of difference does not appear statistically relevant in this small sample size from the four countries in question. This signals that during the early stage of the COVID-19 pandemic, nationalism did not play a significant role in the formulations of societal trust for the four countries in question. However, the results also signal the degree to which the four countries in question are prepared to buffer the negative social and political consequences of the pandemic. The lower levels of political trust and generalized social trust in Slovak and Czechia can lead to significant challenges and, as always, the national frame remains a dominant form of social differentiation that can be utilized in such challenges. Norway and Sweden seem better prepared to buffer negative and political consequences from the pandemic due to the higher levels of governmental, institutional and generalized social trust. 


\section{References:}

Albertazzi, D. and D. McDonnell (eds.) (2008): Twenty-First Century Populism: The Spectre of Western European Democracy. New York: Palgrave Macmillan.

Billig, M. (1995): Banal Nationalism. London: Sage.

Calhoun, C. (2007): Nations Matter: Culture, History and the Cosmopolitan Dream. London: Routledge.

Castano, E. (2004): “European Identity: A Social-Psychological Perspective," in Transnational Identities: Becoming European in the EU. New York: Rowman \& Littlefield; 40 - 58.

Delhey, J. and G. Dragolov (2013): "Why Inequality Makes Europeans Less Happy: The Role of Distrust, Status Anxiety, and Perceived Conflict," European Sociological Review, Vol. 30 (2): 151-165.

Duchesne, S. and A.-P. Frognier (2008): "National and European Identifications: A Dual Relationship" Comparative European Politics, Vol. 6 (2): 143-168.

Eriksen, T. H. (2020): "Norway's response to Covid-19 and the Janus face of Nordic trust." Corona Times, 15 May. https://www.coronatimes.net/tag/norway/

Fox, J. and C. Miller-Idriss (2008): “Everyday Nationhood,” Ethnicities, Vol. 8 (4): 536-576.

Deutsch, F. (2006): "Legitimacy and Identity in the European Union. Empirical Findings from the Old Member States" In Kaina, V. and I. P. Karolewski (eds.), European Identity: Theoretical Perspectives and Empirical Insights, Berlin: LIT Verlag; 149-178.

GINI Index, "Czech Republic” https://data.worldbank.org/indicator/SI.POV.GINI?locations=CZ

GINI Index, "Norway" https://data.worldbank.org/indicator/SI.POV.GINI?locations=NO

GINI Index, "Slovakia: https://data.worldbank.org/indicator/SI.POV.GINI?locations=SK

GINI Index, "Sweden” https://data.worldbank.org/indicator/SI.POV.GINI?locations=SE

Graf, S. and M. Hrebícková (2011): “Accuracy of Slovak national stereotypes: Result of judgment or intuition?” Studia psychologica, Vol. 53: 201-213.

Gullestad, M. (2006): Plausible Prejudice: Everyday experiences and social images of nation, culture and race. Oslo: Universitetsforlaget.

Putnam, R. (2007): "E Pluribus Unum: Diversity and Community in the Twenty-first Century The 2006 Johan Skytte Prize Lecture", Scandinavian Political Studies, Vol. 30 (2): 137-174.

Special Eurobarometer 461: "Designing Europe's Future” (2017) https://ec.europa.eu/commfrontoffice/publicopinionmobile/index.cfm/Survey/getSurveyDetail/surveyKy/2173

Special Eurobarometer 464b: "Europeans' attitudes towards security" (2017) https://ec.europa.eu/commfrontoffice/downloadODP/?D259E84B3570D3270F6B6115188733AA

Wilkinson, R. and K. Pickett (2009): The Spirit Level. Why More Equal Societies Almost Always Do Better. London: Allen Lane. 